\title{
An Epitome of K Venkataraman's Chemistry
}

\section{G Nagendrappa}

\section{Baker-Venkataraman Transformation}

Flavones are well known naturally occurring oxygen heterocycles. They perform important biological functions. Their propensity to show biological activity has led to the development of many synthetic flavonoid drugs. One of the important and widely applicable methods for their synthesis was developed by $\mathrm{K}$ Venkataraman, when he was a lecturer at FC College in Lahore. W Baker of Manchester University published similar work at the same time (1933). The reaction is known as BakerVenkatraman transformation.

It is a simple two-step reaction. In the first step, 2-hydroxyacetophenone or its derivative is treated with an aromatic acid chloride to form an aryl ester, which in the second step, is reacted with a base. The ester is transformed into diaryl 1,3-diketone through an intramolecular rearrangement. Treatment of the latter with an acid leads to the formation of the corresponding flavone. The simplest case of this sequence is shown in Scheme 1.

A variety of 2-hydroxyaryl alkyl ketones and a number of aromatic acid chlorides work very well. Thus a large number of substituted flavones are accessible through this simple synthetic procedure.

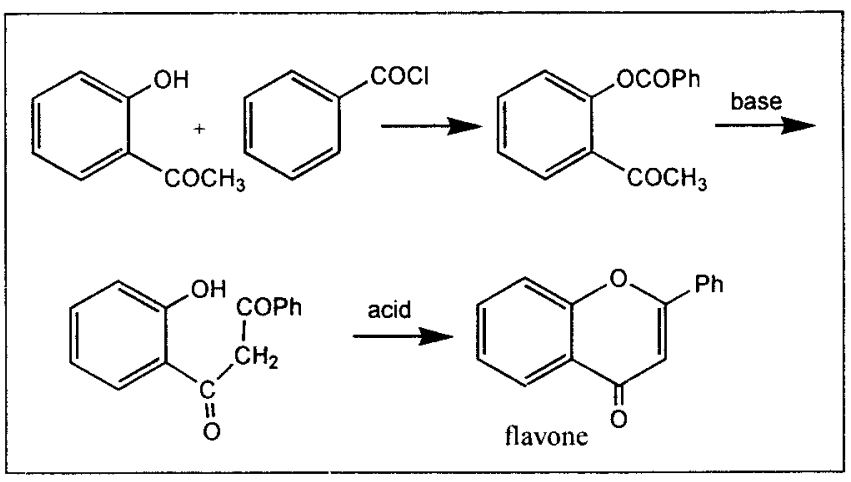

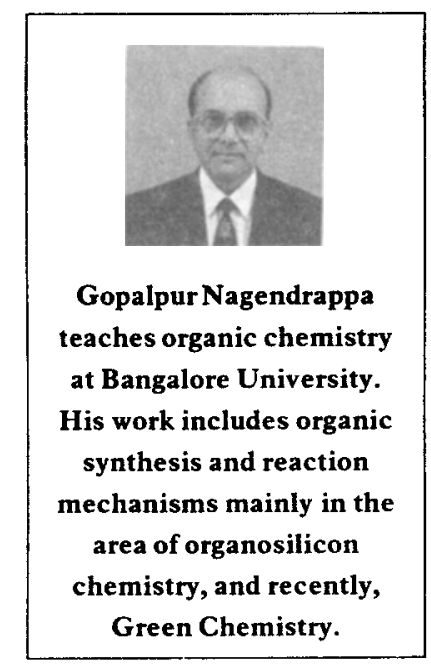

Keywords

Flavones, Baker-Venkataraman transformation, azo and alizarine dyes, Raney nickel-hydrogenation, naphthols.

Scheme 1. 


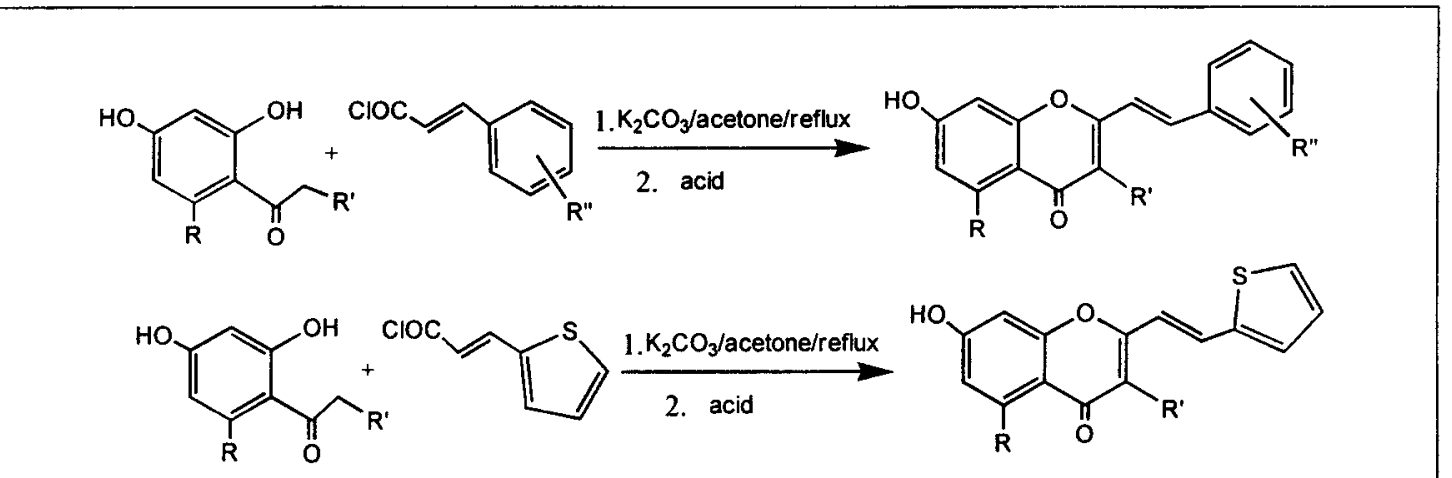

Scheme 2.

A more important contribution of $\mathrm{KV}$, which helped Indian textile industry, was in the area of dyes and textile auxiliaries. The initiative taken by him for research and the support to establish dyestuff industry that found success within a short period, earned him the nickname "the father of dyestuff research in India".
Its contemporary relevance is exemplified by its application in a recent synthesis of styrylchromones, outlined here (Scheme 2). Some of these styrylchromones are cytotoxic to certain leukaemia cells and selective inhibitors of RNA synthesis.

KV's insight into the chemistry of flavones was so deep that he developed many modifications of this basic idea by fine-tuning the variables, such as starting compounds, intermediates and reagents.

His passion for flavones was not restricted to their synthesis alone, but he also devoted a considerable part of his research to isolation of flavonoids from plant sources and elucidation of their structures. He developed methods for selective demethylation of methoxy flavonoids under mild Lewis acid conditions, for introduction of hydroxy groups in oxygen heterocycles involving nitration or azocoupling, replacement of nuclear $\mathrm{OH}$ by $\mathrm{H}$ through tosylation followed by Raney nickel hydrogenolysis and many more such procedures that are useful in structural studies or synthesis.

A more important contribution of $\mathrm{KV}$, which helped Indian textile industry, was in the area of dyes and textile auxiliaries. The initiative taken by him for research and the support to establish dyestuff industry that found success within a short period, earned him the nickname "the father of dyestuff research in India". The textile industries in and around Bombay were greatly benefited. 
The research covered various aspects of the chemistry of dyes, dyeing and related mechanistic studies. It included the synthesis, determination of structures by degradative and spectroscopic methods, and procedures for analysis and estimation of dyes. In the process, he developed several new synthetic procedures, chromatographic separation techniques, and simple, practical methods for the characterisation and estimation of dyes. A few of them are given here as illustrative examples.

\section{Raney Nickel - Hydrogenation}

KV used with good effect Raney nickel catalysed hydrogenation for synthesis as well as determination of structures of dyes and flavones. The method led to clean desulphurisaion of sulphonic acid dyes, tosylate derivatives of phenolic compounds, and other sulphur containing compounds. The products formed were better amenable for analysis by NMR and mass spectral studies (Scheme 3). Many anthraquinone dyes and violanthrones were analysed using this procedure. The reaction of thiobenzimidazole derivative shown in equation (3) became the basis for reductive alkylation of amines using alcohols.

\section{Hydrolysis of Anilides}

Anilides are difficult to hydrolyse. KV developed a method for

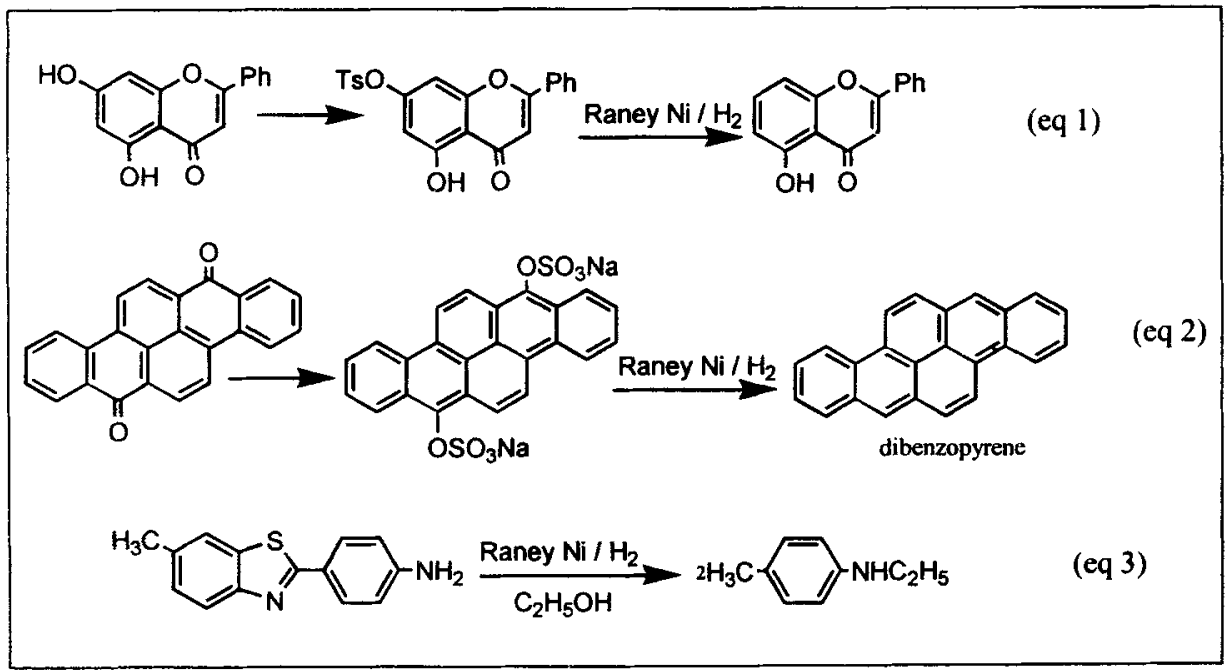

Scheme 3.
KV developed several new synthetic procedures, chromatographic separation techniques, and simple, practical methods for the characterisation and estimation of dyes. 
<smiles>COc1cc(Br)ccc1NC(=O)c1cc2ccccc2cc1O</smiles>

Brenthaol BA (a Naphtol)<smiles>O=C1c2ccccc2C(=O)c2c(O)c(O)cc(Cl)c21</smiles>

Chioro / bromo-alizarine<smiles>Cc1cc(O)c2c(c1O)C(=O)c1cccc(O)c1C2=O</smiles>

Islandicine<smiles>Nc1cc2c(=O)c3cc(Cl)cc(Cl)c3[nH]c2c2c1C(=O)c1ccccc1C2=O</smiles>

Indanthrine Turquoise Blue $3 \mathrm{GK}$

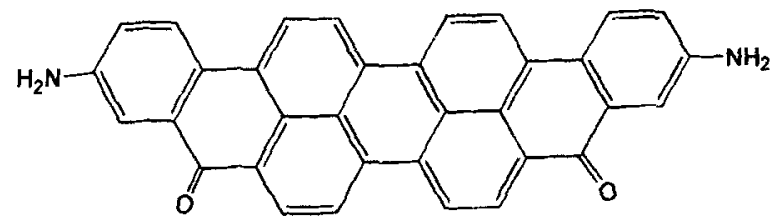

Diaminodibenzoanthrone

Figure 1.

One of the important research programmes of $\mathrm{KV}$ was the synthesis of azo and alizarine dyes. the facile hydrolysis of the anilides of o-hydroxy carboxylic acids. They were treated with 2,4-dinitro-chlorobenzene and the resultant $\mathrm{N}$-2,4-dinitrophenyl derivatives underwent hydrolysis under mild conditions.

\section{Synthesis of Azo Dyes}

One of the important research programmes of $\mathrm{KV}$ was the synthesis of azo and alizarine dyes. He made modifications in the diazotisation procedure in the case of some amines, and used it not only for the synthesis of several new azo dyes but also for altering the shades and improving the fastness of cutch dyeings and calico printing. Among other dyes were naphthol derivatives (Naphtols), alizarins, indanthrones, and benzanthrones. A few of them are given in Figure 1 as examples.

The diazocoupling of phenolic compounds was used to introduce a hydroxy group in a specific position and to elucidate structures, (Scheme 4). 


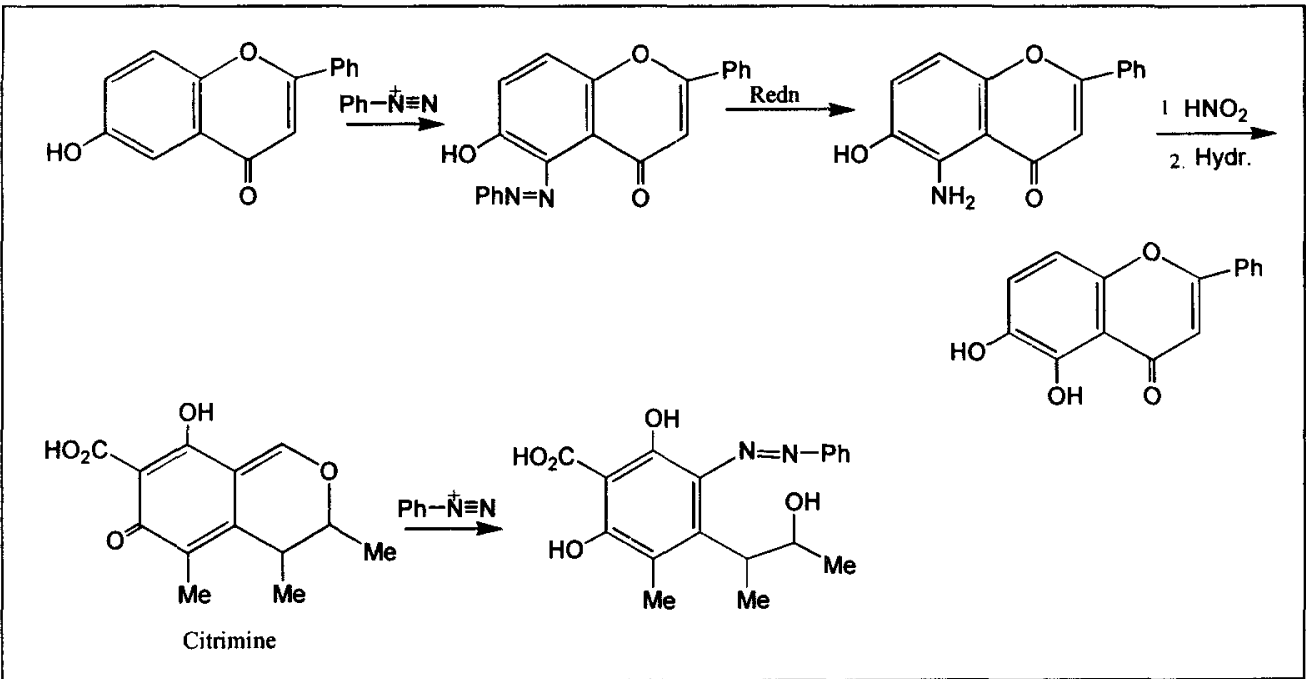

\section{Natural Pigments}

Scheme 4.

A number of natural pigments belonging to anthraquinonoid group, such as laccaic acids A and B present in lac dye, were isolated and characterised.<smiles>[R]CCc1cccc(-c2c(O)c(O)c3c(c2O)C(=O)c2c(cc(O)c(C(=O)O)c2C(=O)O)C3=O)c1</smiles>

\section{Reaction Mechanism in Dyes and Dyeing}

Reactive dyes are a class of dyes that contain the $\beta$-sulphatoethyl sulphone functional group, (Dye) $-\mathrm{SO}_{2}-\mathrm{CH}_{2}-\mathrm{CH}_{2}-\mathrm{OSO}_{2} \mathrm{H}$, which is responsible for bonding with the fabric in presence of alkali. KV provided direct physical evidence, particularly by NMR data, for the formation of ether bond between the reactive dye and cellulose, and proposed the following mechanism for its formation involving the intervention of allylic carbon that

Reactive dyes are a class of dyes that contain the $\beta$ sulphatoethyl sulphone functional group, (Dye)- $\mathrm{SO}_{2}-$ $\mathrm{CH}_{2}-\mathrm{CH}_{2}-\mathrm{OSO}_{2} \mathrm{H}$, which is responsible for bonding with the fabric in presence of alkali. KV provided direct physical evidence, particularly by NMR data, for the formation of ether bond between the reactive dye and cellulose. 


$$
\begin{aligned}
& \text { } \\
& \text { a reactive dye } \\
& \text { Dye }-\stackrel{\mathrm{O}_{\|}^{\|}}{\mathrm{O}}-\overline{\mathrm{CH}}-\mathrm{CH}_{2}-\mathrm{OSO}_{2} \mathrm{Na} \longrightarrow \mathrm{Dye}-\stackrel{\mathrm{O}_{\|}^{-}}{\mathrm{O}^{-}}=\mathrm{CH}-\mathrm{CH}_{2}-\mathrm{OSO}_{2} \mathrm{Na} \stackrel{\text { cellulose }(-\mathrm{OH})}{\longrightarrow}
\end{aligned}
$$

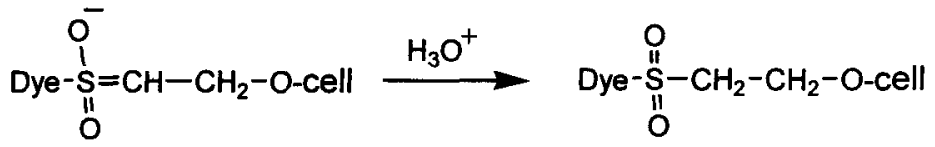

\section{Scheme 5.}

In order to develop new textile auxiliary agents, KV experimented with soaps, Turkey red oil, Monopole oils, and the products obtained from castor oil on its reaction with sulphuric acid. facilitates $\mathrm{S}_{\mathrm{N}} 2$ displacement by cellulose -OH group, (Scheme 5).

In another study, he showed that not all oxycelluloses, but only those containing $\beta$-ketonic acid or aldehyde group would couple with dizonium salts. He investigated the factors that influence the azo-hydroxy tautomerism in $o$-hydroxyazo dyes, and demonstrated the deshielding effect of azo group of azo dyes in their NMR spectra.

\section{Textile Auxiliary Agents}

The textile auxiliary agents perform varied functions. They help dispersion of dyes, wetting out of fibres and level dyeing, and are used for wetting, detergency, emulsifying power and protective colloidal action during dyeing process. In order to develop new textile auxiliary agents, $\mathrm{KV}$ experimented with soaps, Turkey red oil, Monopole oils, and the products obtained from castor oil on its reaction with sulphuric acid.

\section{Analytical Procedures}

Separation, purification, and analysis of dyes were an important research activity pursued by $\mathrm{KV}$. He developed column chromatographic technique under hot condition $\left(100-150^{\circ} \mathrm{C}\right)$ and used highly polar, unconventional solvents in order to solve the 
problem of solubility and elution of dyes. He applied paper chromatographic technique for the analysis of aminoanthraquinones, and used adsorption on cellulose powder for separation of vat dyes with such unusual solvent as aqueous tetraethylene pentamine containing hydrosulphite. He studied the influence of $-\mathrm{OH}$ group in azo dyes on their adsorption properties on alumina.

$\mathrm{KV}$ developed some very simple methods for the analysis and estimation of dyes and related compounds. For example, to determine the protective colloidal action of surface active compounds, he introduced Congo Rubine Number, which is simply the weight of $\mathrm{NaCl}$ required to change the colour of Congo Rubine from red to lilac under standard conditions. He found, in another study, that naphthols could be estimated by precipitating them by acidifying their alkaline solution in water or aqueous alcohol and weighing the precipitate.

\section{Conclusion}

Krishnaswami Venkataraman's contribution to the chemistry of flavones and other natural products, and his work on dyes is not limited to the examples very briefly recorded here. His work covered also the dyes developed for colouring cements, dyemetal complexes, health concerns in case of food colourants, and many other aspects. He put his heart, soul and brainpower for the growth and promotion of his chosen field of research, a good part of which is important even today.

\section{Suggested Reading}

[1] K Venkataramn (Ed), The Chemistry of Synthetic Dyes, Academic Press, Vol I \& II, 1952, Vol III - VIII, 1971- 1978.

[2] K Venkataraman (Ed), The Analytical Chemistry of Synthetic Dyes, John Wiley \& Sons, 1977.

[3] Nitya Anand, Biographical Memoirs, INSA, New Delhi.

[4] A M S Silva, DCG A Pinto, JA S Cavaleiro, A Levai, T Patonay, ARKAT USA, http://www.arkat-usa.org/ark/journal/2004/107_Antus/sa-1032R/ 1032R.asp
KV developed some very simple methods for the analysis and estimation of dyes and related compounds. He found, in another study, that Naphthols could be estimated by precipitating them by acidifying their alkaline solution in water or aqueous alcohol and weighing the precipitate.
Addresss for Correspondence Gopalpur Nagendrappa Department of Chemistry Bangalore University Bangalore 560001 , India. Email: nagendrappa@vsni.net 